\title{
Mobile Media Usage Patterns, Advertising Type Preference, Traits of Advertising, and Mobile Advertising Effects: A Case of South-Eastern Korean Residents
}

\author{
Joon-Ho Lee ${ }^{1}$, Sang-Hyun Hwang ${ }^{2}$ \\ ${ }^{1}$ Professor, Department of Communication \& Media, Dong-eui University, Korea, joonlee@deu.ac.kr \\ ${ }^{2}$ Assistant Professor, Department of Advertising \& PR, Dong-eui University, Korea, moca@deu.ac.kr
}

Corresponding author: Joon-Ho Lee

\begin{abstract}
The purpose of this study is to empirically explore how smart phone using patterns, mobile advertising type preferences, and the user perception of advertising traits affect advertising acceptance and intention to purchase. A survey was conducted on 349 respondents who resided in south-eastern Korea using a series of multiple linear regression analyses that tried to explore linear causal relationships between multiple predicting variables and a dependent variable. The following results and implications were found. First, frequent seekers of information/news on smart phones are more likely to favorably receive mobile advertising messages and to have intent on buying these advertised products. Second, advertisements in a video format or those that include a coupon or discount offer seem to be relatively more effective than the other types of advertisements. Third, both advertising acceptance and purchase intention levels tend to increase when advertisements are perceived to be more compensatory, convenient, or immersive. In conclusion, these results are significant for both mobile advertising planners and practitioners pursuing extended, advanced, and practical ideas and insights.
\end{abstract}

Keywords: Mobile Advertising, Smart Phone Use, Advertising Type, Ad Attitude, Purchase intention

\section{Introduction}

The worldwide introduction and rapid adoption of smart media, including smart phones, tablet PCs, and smart TVs from 2007 through 2010s have radically impacted the use, production, and distribution of media content and commercial messages. As of 2020, most people have adopted smart phones that are supported by high speed Internet services. This revolution of networks and devices, especially with the widespread adoption of mobile communication media, has changed nearly every way we process our individual, social, economic life. This includes our daily advertising consumption patterns.

Statistics and reports throughout Korea clearly show that the traditional advertising media, such as those of newspaper, publishing, and broadcasting, have become minor platforms for advertising content, whereas the new on-line media represented by the Internet and mobile devices have become the major advertising media. Newspaper readership has fallen below 20\% since 2018 and this is a remarkable trend when we consider that there was a national readership of $80 \%$ in 2000 and $60 \%$ in 2010. In contrast the smart phone penetration rate among Korean people under 60 is almost $100 \%[1]$. In accordance with this transformation, total advertising revenue for mobile media has increased to 5 trillion won with there

Received: February 15, 2021; 1st Review Result: March 31, 2021; 2nd Review Result: May 17, 2021 Accepted: June 30, 2021 
being a two-digit percentage of average annual growth whereas the total of other more traditional forms of media having decreased or stagnated since 2015[2].

These phenomena are clearly reflective of dramatic changes in media consumption, production, distribution, content, and format, and indicate our growing dependency on smart media for almost every aspect of our daily lives. Smart media can now accommodate nearly all types of information, entertainment, administrative and commercial usage, and have led people to become over-dependent on these new forms of media[3]. Also, a $67.2 \%$ majority of Korean consumers think that smart phones are the most essential medium[1]. This personalized ubiquitous medium provides an unlimited attractive space for targeting advertisements.

Since 2007, the rapid development and penetration of smart mobile devices in the marketplace have dramatically increased the usage of mobile devices, and with this shift so too has the focus of advertising delivery been entirely transformed. Even though many companies now use mobile advertising, its effects have not been completely explored. Most prior speculation and empirical studies about mobile advertising have focused on external and visible factors, rather than on individual traits or differences among users when analyzing the effectiveness of smart phone advertising[4].

It is now vital to empirically explore how people perceive and consume mobile media and advertising, and how these perceptions and consumption trends influence people in terms of acceptance of advertising and intention to purchase advertised products or services. Therefore, this study is intended to analyze the characteristics of mobile media usage patterns, advertising type patterns, mobile advertising user perceptions as well as the effects of these characteristics on advertising acceptance and the subsequent intention to purchase.

\section{Literature Review}

\subsection{The Rise and Dominance of Mobile Advertising Media}

The shapes and characteristics of advertising have persistently changed in accordance with changes in the media environment and market trends. Advertisers pursue wide exposure for their products and services using the most effective methods and strategies, however, no advertising strategy is universal in different media environments. Therefore, it is necessary to understand the contemporary media advertising environment and to develop suitable plans and content, that make the effectiveness of advertising paramount[5].

The initial post-feature phone is widely known as Apple's iPhone which was introduced in 2007. Since then, a number of competing manufacturers and application developers have also rapidly launched new serial versions of smart devices and applications for billions of users worldwide. The total number of users has dramatically increased and it has reached its saturation point in many countries in the 2020s. In case of Korea, $93.1 \%$ of the entire population over the age of 12 has adopted a smart phone and use it every day. Also, the smart phone penetration ratio and real usage ratio among users who are relatively older have rapidly increased. This has resulted in a fast increase in mobile advertising revenue and an overall dominance of mobile media in the marketplace as shown in [Table 1].

[Table 1] Annual Media Advertising Expenditures in Korea (unit: million Won)

\begin{tabular}{|c|c|c|c|c|c|c|c|}
\hline Media/Year & 2015 & 2016 & 2017 & 2018 & 2019 & $\begin{array}{c}2020 \\
\text { (estimated) }\end{array}$ & $\begin{array}{c}2021 \\
\text { (estimated) }\end{array}$ \\
\hline Broadcasting & $4,463,966$ & $4,135,069$ & $3,950,057$ & $3,931,829$ & $3,771,046$ & $3,556,984$ & $3,468,550$ \\
\hline Newspaper/Print & $2,329,706$ & $2,319,341$ & $2,310,264$ & $2,347,956$ & $2,372,993$ & $2,254,852$ & $2,232,215$ \\
\hline
\end{tabular}




\begin{tabular}{|c|c|c|c|c|c|c|c|c|}
\hline \multirow{2}{*}{ On-Line } & Total & $3,427,814$ & $4,154,724$ & $4,775,137$ & $5,717,205$ & $6,521,929$ & $7,273,275$ & $7,956,911$ \\
\cline { 2 - 8 } & Internet & $2,053,407$ & $2,173,087$ & $1,909,192$ & $2,055,449$ & $1,871,643$ & $1,748,841$ & $1,799,048$ \\
\cline { 2 - 9 } & Mobile & $1,374,407$ & $1,981,637$ & $2,865,945$ & $3,661,755$ & $4,650,286$ & $5,524,434$ & $6,157,863$ \\
\hline \multicolumn{2}{|c|}{ Outdoor } & $1,061,274$ & $1,088,532$ & $1,305,948$ & $1,329,898$ & $1,256,765$ & 989,906 & $1,007,713$ \\
\hline \multicolumn{2}{|c|}{ Other } & 507,873 & 464,991 & 412,056 & 428,999 & 504,196 & 474,518 & 477,130 \\
\hline \multicolumn{2}{|c|}{ Total } & $11,790,634$ & $12,162,657$ & $12,753,463$ & $13,755,886$ & $14,426,928$ & $14,549,536$ & $15,142,519$ \\
\hline
\end{tabular}

Source: https://adstat.kobaco.co.kr/sub/expenditure_data_search.do

On-line advertising revenue now accounts for over half of total Korean domestic media advertising expenditure due to the rapid growth of mobile advertising revenue in the past several years. Since Internet advertising expenditure is static over time, mobile advertising itself is expected to occupy over $50 \%$ of the entire media advertising market soon. This remarkable growth of the share of mobile advertising revenue is possible due to user dependency on smart phone resulting from changes in lifestyle on the one hand, and due to the past decrease in traditional media (newspaper and broadcasting) advertising revenue on the other hand.

\subsection{Smart Phone Usage Patterns}

When studying advertising effects and establishing advertising strategy, it is first important to categorize general consumers based on their lifestyles or media use patterns. Based on prior relevant research about mobile advertising and cognitive traits among users, content preference (preference for content of advertisements to which they are exposed) is most positively related to a consumer's perceived informative, entertainment values concerning mobile advertisements. These values depend on each user's individual differences and also mediate the effects of content preference on attitude toward the ads.

The lifestyle of media users frequently determines their personal interests and consumption patterns for media content and advertisements. In terms of using media advertising, one study found that a user's lifestyle can be divided into 4 types; social leader type, leisure value investment type, desire for leisure type, and pragmatic type[6]. Another study about smart media usage patterns showed that there were 5 major patterns of smart phone use; personal communication, news and information gathering, works, visual and audio content, and shopping and commercial use[7].

These differences in types of lifestyle and in usage patterns of the media have been known to contribute to causing differences in advertising type preference and in shaping attitude toward advertising. Subsequently, these differences result in different levels of advertising effects. For example, in the leisure value investment-oriented user group who tend to use media mainly for shopping and commercial purposes had more positive attitude toward advertisements and the power of advertising than others. In contrast, in the social leader and pragmatic user groups who tend to use media mainly for the purpose of news and information seeking and works had less positive attitude toward advertisements.

\subsection{Factors for Smart Phone Advertising Effects}

Besides the purpose and patterns of smart phone usage, three more major factors or elements have been suggested and explored in terms of their contribution to mobile advertising effects; (1) advertising type, (2) perceived traits of advertising, and (3) advertising attitude.

First, types of mobile media advertising were categorized according to their ways to express (text, 
banner, audio/video), ways to transmit (push, pull), and their message type (content, transaction, response, location, timing, and media-mix)[10]. However, they were perceived and categorized into two types in general (format and content) and widely used in the prior studies. The format of mobile advertising consisted of shape, lay-out, and interactivity, while content consisted of product or service, theme, cognitive or affective, positive or negative, traits of model (celebrity), and so on.

Second, the most frequently analyzed elements of the user's perception of advertising by previous studies were those of; information, preference, credibility, customization, situation, convenience, economy (efficiency), interest (entertainment), experience, compensation, immersion, rejection, and so on.

Third, the advertising attitude is a composite of the consumer's learned tendency or orientation to consistently respond to advertising stimuli favorably or unfavorably after having being exposed to an advertisement. The consumer came to have certain attitude toward advertising and its products and brands in terms of a variety of attitude dimensions. This attitude in turn affected their subsequent purchase intention[9].

In terms of effects of advertising in the applied sense, actual purchases of advertised products were the final destination of advertising behaviors and strategies. However, it was more important to find out a consumer's intention to concentrate on advertising, to favorably admit its messages, and to form an intention to buy. There has been an abundance of research done to explore possible attitude factors for advertising effects. This has used a variety of research frameworks such as reception or rejection of advertising messages and purchase intention which are based on flow theory[10], on the technology acceptance model[11], and on the advertising value model[12].

\subsection{Theoretical Framework for Analysis}

Smart phones have become the main advertising medium due to its increasing usage and advertising revenue, so advertising effects of the medium need to be examined carefully. For this purpose, it is necessary to analyze the causal relationship between factors and the effects of adverting on a smart phone. When summarizing literature and prior research findings, three main factors were proposed;

1) consumers' daily smart phone usage pattern,

2) their advertising type preference,

3) their perception of various traits of advertising

These in turn influence two-step advertising effects, as follows;

1) advertising acceptance, meaning possibility or willingness to pay attention and admit advertising messages

2) purchase intention, meaning being ready to buy advertised product or services

The following theoretical model was proposed based on the findings of prior studies shown above ([Fig. 1]).

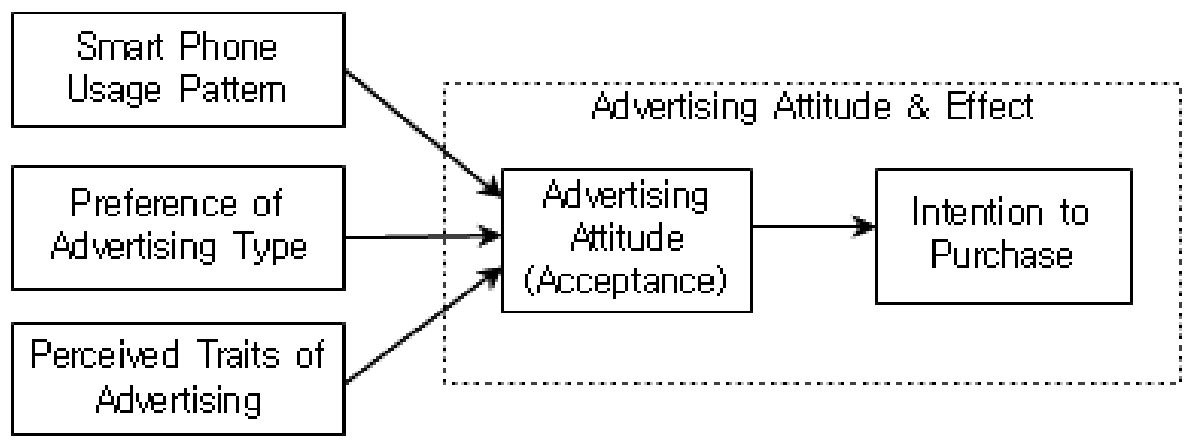

[Fig. 1] Smart Phone Advertising Effect Model for Analysis 


\subsection{Research Question}

Based on the purpose of the study and the new theoretical framework, the following research questions are proposed.

RQ 1. What is the relationship between a user's traits of smart phone usage and the effectiveness of smart phone advertising?

RQ 2. What is the relationship between a user's preference for types of advertising and the effectiveness of smart phone advertising?

RQ 3. What is the relationship between a user's perceived traits of advertising and the effectiveness of smart phone advertising?

\section{Method}

\subsection{Research Tool}

This study used an interview survey to gather sufficient useful data on (1) daily smart phone usage, (2) advertising type preferences, (3) perception of advertising traits, (4) advertising acceptance, and (5) purchase intention. The questionnaire consisted of following six parts and most of them were measured by 5-point Likert scales. A draft of questionnaire was made based on prior studies on smart media advertising and operationalizations of each variable for measurement. Then it was consulted and validated by an advertising research professor and an expert.

1) 23 questions that asked about daily purposive usage of their smart phones which were later factor analyzed by using varimax rotation techniques and regrouped into six dimensions - 'work/education,' 'media/content,' 'shopping/leisure,' 'information/news,' 'human relation,' 'convenience': all the factor loadings of each dimension was over .5 and their Cronbach's alpha reliability measures were over .7, satisfying the minimum standard to consist an independent dimension or a factor

2) Degree of preference of 12 advertising types: 7 format types (voice/ARS, text/SMS, graphic/icon, video, bar/QR code, coupon/discount) and 5 content types (household goods, electronics/IT, durable goods, work/hobby, service/leisure)

3) 33 questions that asked about 11 advertising attitude dimensions: 'situation,' 'information,' 'customization,' 'convenience,' 'economy/efficiency,' 'interest/entertainment,' 'experience,' 'compensation,' 'rejection,' 'immersion,' and 'credibility': Each dimension consists of 3 questions and their Cronbach's alpha reliability measures within each dimension were over .8 , satisfying the minimum standard to consist an independent dimension or a factor

4) Advertising acceptance level: level of attention to and favor of advertising

5) Purchase intention

6) Demographics.

\subsection{Sampling and Data Collection}

A hybrid sampling method, consisting of purposive sampling and stratified sampling, was employed. A total of 20 trained interviewers visited the subjects and received answers from the respondents. The interviewers visited and asked 400 randomly selected people who lived in south-eastern Korea (Busan City, Ulsan City, and Gyeongnam Province) and who had experienced reading and watching advertising messages with their smart phones.

The sample consisted of balanced numbers of males $(53.3 \%)$ and females $(46.7 \%)$ while controlling demographic characteristics for age $(9.8 \%$ were $10 \mathrm{~s}, 29.7 \%$ were $20 \mathrm{~s}, 29.0 \%$ were $30 \mathrm{~s}, 19.5 \%$ were $40 \mathrm{~s}$, and $12.0 \%$ were $50 \mathrm{~s}$ and older), education, occupation, and income, proportionately compatible with 
national population statistics. The survey was conducted in January, 2020 throughout the South-Eastern metropolitan areas of Korea. The total number of respondents was 400, however, 51 of them were excluded because they skipped answering an unacceptable number of essential questions, and the final size of the sample for actual analyses was 349 respondents. This study used a randomized interview survey.

\subsection{Data Analysis}

To gain solutions to these three research questions, a series of multiple linear regression analyses were conducted to explore linear relations among three factors (independent variables) and two advertising effects (dependent variables). Multiple linear regression, also known simply as multiple regression, is a statistical technique that uses several explanatory (independent) variables to predict the outcome of a criterion (dependent) variable.

The goal of multiple linear regression is to model the linear relationship between multiple independent variables and a dependent variable by measuring variances and coefficients of explanatory variables and judging whether they are powerful enough to explaining (expecting) the state (variance) of the dependent variable. The collected data were coded and calculated by using SPSS v.25.

\section{Results}

The RQ 1. examined the relationship between a user's traits of daily purposive smart phone usage and the effectiveness of smart phone advertising ([Table 2]). In general, all the smart phone usage patterns or traits variables explained and predicted $7.2 \%$ of the total variance of advertising acceptance, and $6.4 \%$ of that of purchase intention $\left(\mathrm{R}^{2}=.072\right.$ and $\mathrm{R}^{2}=.064$, respectively).

[Table 2] Multiple Regression between Smart Phone Usage Pattern and Advertising Effects (N=349)

\begin{tabular}{|c|c|c|c|c|c|c|c|c|}
\hline Ad Effects & & Advertisi & ceptan & & & Purcha & ention & \\
\hline Usage Pattern & $\beta$ & $\mathrm{t}$ & $\mathrm{p}$ & $\mathrm{R}^{2}$ & $\beta$ & $\mathrm{t}$ & $\mathrm{p}$ & $\mathrm{R}^{2}$ \\
\hline Work/Education & -.138 & -1.989 & $.040^{*}$ & \multirow{6}{*}{.072} & -.075 & -1.182 & .238 & \multirow{6}{*}{.064} \\
\hline Media/Content & .094 & 1.587 & .113 & & .021 & .350 & .726 & \\
\hline Shopping/Leisure & .095 & 1.580 & 115 & & .133 & 1.969 & $.045^{*}$ & \\
\hline Infomation/News & .153 & 2.292 & $.022 *$ & & .140 & 1.995 & $.038^{*}$ & \\
\hline Human Relation & .038 & .573 & .567 & & .110 & 1.675 & .095 & \\
\hline Convenience & -.135 & -1.977 & $.042 *$ & & -.062 & -.943 & .346 & \\
\hline
\end{tabular}

Those who used the device mainly for the purposes of work/education or convenience were less likely to receive mobile advertising $(\beta=-.138 ;-.135, \mathrm{p}<.05)$, whereas those who used their mobile phone for information/news seeking were more likely to receive mobile advertising messages $(\beta=.153, p<.05)$. In addition, users who used the device mainly for shopping/leisure, information/news tended to show a higher possibility to purchase advertised products $(\beta=.133 ; .140, \mathrm{p}<.05)$.

[Table 3] shows the result of another multiple regression analyses giving answers to the RQ 2 examining the relationship between a user's preference for types of advertising and the effectiveness of 
smart phone advertising. The table presents causal relationships between advertising type preference and their subsequent advertising effects. In terms of the explaining and predicting power of the 12 independent variables on each of the two dependent variables, $32.2 \%$ and $21.9 \%$ were measured $\left(\mathrm{R}^{2}=.322\right.$ and .219 , respectively).

Those users who preferred and enjoyed mobile advertising in video format were most likely to accept mobile advertising messages $(\beta=.299, \mathrm{p}<.05)$, and those who preferred advertising for service/leisure products, coupon/discount advertising, and advertising to promote household goods were more likely to receive mobile advertising in order $(\beta=.251, \mathrm{p}<.01 ; \beta=.142 ; .119, \mathrm{p}<.05)$. In terms of the factors affecting purchase intention, those who preferred coupon/discount type advertising $(\beta=.228, \mathrm{p}<.01)$ and video format of advertising $(\beta=.200, p<.05)$ were more likely to show their intention to buy advertised products. However, users who preferred text or SMS advertising mostly were not likely to show their intention to buy products $(\beta=-.250, \mathrm{p}<.01)$.

[Table 3] Multiple Regression between Advertising Type Preference and Advertising Effects ( $N=349)$

\begin{tabular}{|c|c|c|c|c|c|c|c|c|}
\hline Ad Effects & & lvertisin & Acceptanc & & & Purchas & ntion & \\
\hline $\begin{array}{l}\text { Ad Type } \\
\text { Preference }\end{array}$ & $\beta$ & $\mathrm{t}$ & $\mathrm{p}$ & $\mathrm{R}^{2}$ & $\beta$ & $\mathrm{t}$ & $\mathrm{p}$ & $\mathrm{R}^{2}$ \\
\hline Voice/ARS & -.021 & -.307 & .759 & \multirow{12}{*}{.322} & .048 & .645 & .519 & \multirow{12}{*}{.219} \\
\hline Text/SMS & -.040 & -.567 & .571 & & -.250 & -3.204 & $.001 * *$ & \\
\hline Graphic/Icon & -.116 & -1.640 & .102 & & -.032 & -.419 & .675 & \\
\hline Video & .299 & 4.228 & $.000 * * *$ & & .200 & 2.592 & $.010^{*}$ & \\
\hline Code (Bar/QR) & .116 & 1.813 & .071 & & .019 & .269 & .788 & \\
\hline Coupon/Discount & .142 & 2.358 & $.019 *$ & & .228 & 3.467 & $.001 * *$ & \\
\hline Banner & -.088 & -1.387 & .166 & & -.060 & -.873 & .383 & \\
\hline Household Goods & .119 & 1.977 & $.049 *$ & & .058 & .881 & .379 & \\
\hline Electronics/IT & .078 & 1.231 & .219 & & .061 & .886 & .376 & \\
\hline Durable Goods & .007 & .118 & .906 & & .042 & .640 & .523 & \\
\hline Work/Hobby & .045 & .620 & .536 & & .112 & 1.403 & .161 & \\
\hline Service/Leisure & .251 & 3.343 & $.001 * *$ & & .153 & 1.867 & .063 & \\
\hline
\end{tabular}

The RQ 3. of the study was "What is the relationship between a user's perceived traits of advertising and the effectiveness of smart phone advertising?" This question was suggested in order to explore how the advertising is effective depending on a user's 11 different attitude dimensions. The results of this question are shown in [Table 4].

The independent variable set of perceived traits of advertising explained $37.1 \%$ of total variance for the advertising acceptance variable and $36.6 \%$ of that of the purchase intention $\left(\mathrm{R}^{2}=.371\right.$ and .366 , respectively). This shows that the independent variable group of the perception of advertising traits had more powerful predicting power on the dependent variables than the other two groups of factors above (smart phone usage pattern and advertising type preference).

Among the perceived traits of advertising variables, 'compensation' was most decisive and positive in predicting both variables of effects $(\beta=.254 ; \beta=.260, p<.001)$, and 'convenience' was the second powerful predictor $(\beta=.173, \mathrm{p}<.01 ; \beta=.216, \mathrm{p}<.001)$. The third powerful predictor was the 'immersion' 
dimension $(\beta=.167, \mathrm{p}<.01 ; \beta=.132, \mathrm{p}<.05)$. The 'rejection' was another significant factor that negatively influenced the advertising acceptance $(\beta=-2.284, \mathrm{p}<.05)$, but did not impact the purchase intention. Last, 'economy/efficiency' was one of significant positive predictors of the purchase intention $(\beta=3.082$, $\mathrm{p}<.01$ ), but was not significant in affecting the advertising acceptance.

[Table 4] Multiple Regression between Perceived Traits of Advertising and Advertising Effects ( $N=349)$

\begin{tabular}{|c|c|c|c|c|c|c|c|c|}
\hline \multirow{2}{*}{$\begin{array}{l}\begin{array}{l}\text { Ad Effects } \\
\text { Perceived } \\
\text { of Ad }\end{array} \\
\text { Traits }\end{array}$} & \multicolumn{4}{|c|}{ Advertising Acceptance } & \multicolumn{4}{|c|}{ Purchase Intention } \\
\hline & $\beta$ & $\mathrm{t}$ & $\mathrm{p}$ & $\mathrm{R}^{2}$ & $\beta$ & $\mathrm{t}$ & $\mathrm{p}$ & $\mathrm{R}^{2}$ \\
\hline Situation & .055 & 1.058 & .291 & \multirow{11}{*}{.371} & .018 & .337 & .736 & \multirow{11}{*}{.366} \\
\hline Information & .082 & 1.198 & .232 & & -.022 & -.323 & .747 & \\
\hline Customization & .120 & 1.693 & .091 & & .059 & .836 & .404 & \\
\hline Convenience & .173 & 3.208 & $.001 * *$ & & .216 & 3.977 & $.000 * * *$ & \\
\hline Economy/Efficiency & .027 & .501 & .617 & & .168 & 3.082 & $.002 * *$ & \\
\hline Interest/Entertainment & -.027 & -.463 & .643 & & .069 & 1.118 & .239 & \\
\hline Experience & .034 & .508 & .611 & & .027 & 1.070 & .285 & \\
\hline Compensation & .254 & 5.268 & $.000 * * *$ & & .260 & 5.368 & $.000 * * *$ & \\
\hline Rejection & -.109 & -2.284 & $.023 *$ & & -.029 & -.601 & .548 & \\
\hline Immersion & .167 & 2.793 & $.006^{* *}$ & & .132 & 2.196 & $.029 *$ & \\
\hline Credibility & .045 & .762 & .446 & & -.028 & -.484 & .629 & \\
\hline
\end{tabular}

[Table 5] Relationship between Advertising Acceptance and Purchase Intention ( $N=349)$

\begin{tabular}{|c|c|c|c|c|c|}
\hline \multirow{2}{*}{} & \multicolumn{5}{|c|}{ Purchase Intention } \\
\cline { 2 - 6 } & $\beta$ & $\mathrm{t}$ & $\mathrm{P}$ & partial r & $\mathrm{R}^{2}$ \\
\hline Ad acceptance & .699 & 18.113 & $.000^{* * *}$ & .699 & .488 \\
\hline
\end{tabular}

$* * * \mathrm{p}<.001$

Additionally, the relationship between the two advertising effect variables was examined ([Table 5]). A partial correlation coefficient (partial r) between the two is scored .699, and advertising acceptance occupied $48.8 \%\left(\mathrm{R}^{2}=.488\right)$ of the total variance of purchase intention. They were proven very strongly related each other.

Considering the results of multiple regression analyses shown on the four tables above ([Table 2], [Table 3], and [Table 4]), it was found that explaining or predicting power $\left(\mathrm{R}^{2}\right)$ of the three independent variable groups was slightly stronger on the advertising acceptance than on the purchase intention. In addition, advertising type preference and perceived traits of advertising are more decisive factors than smart phone usage pattern. This means that the independent variables explored in this study proved that they were more likely to directly affect the advertising attitude (acceptance) than the purchase intention. It also means that those advertisements which provide consumers with more attention, convenience, benefit, and attraction can be successful. Also, as there was a strong causal relation between the advertising acceptance and the purchase intention [Table 5], the advertising attitude proved an important mediating variable between the independent variable sets and the purchase intention. These supported 
the findings of prior research and the research framework of this study.

\section{Conclusion}

The study empirically explored how smart phone usage patterns, advertising type preferences, and the user perception of mobile advertising affect their advertising acceptance and intention to purchase. To review the main findings of the study, the following kinds of users are more likely to accept mobile advertising and to intend to purchase: (1) those who uses mobile phone for information and news, (2) those who prefer video type and discount type advertising, and (3) those who perceive that advertising provides convenience, compensation and immersion when they consider purchasing advertised products.

The results of this study can provide advertising planners and practitioners with some extended, advanced, and meaningful ideas and insights. It was found that it is important to recognize the proven key factors raising the intended effects of advertising in both the advertising attitude and the purchase intention which are threefold;

1) smart phone use motivations or usage pattern for information/news seeking

2) preference for video and coupon/discount type advertising

3) pser's positive perceptions of compensation, convenience, and immersion

The current research remains incomplete until subsequent empirical studies, such as micro-level experiments are conducted that could examine mobile advertising effects in specific conditions and circumstances, and could more clearly explore the causality of relationships among these variables, especially clarifying the power of the advertising attitude (perceived traits) in moderating the numerous independent variables and the purchase intention. Also, it will be a point of interest to generate predictions about how the mobile advertising will displace or co-evolve with other media advertising in this highly competitive and unlimited market.

\section{References}

[1] Annual Research of Broadcast Media Usage Patterns, Korean Communications Commission, (2020)

[2] Korea Advertising Expenditure Research, Korea Broadcast Advertising Commission, (2020)

[3] N. Eom, Current State of Over-Dependency on Smart Phone and Its Prevention and Elimination, KISO Journal, March $28(2018)$

[4] M. K. Kim, S. M. Lee, Who Respond Which Cues in Mobile Advertising: Effects of Image Preference on the Perceived Value of and Attitude Towards Mobile Advertising, Advertising Research, (2017), Vol.114, pp.42-67, DOI:10.16914/ar.2017.114.42

[5] J. S. Koo, J. H. Lee, W. S. Lee, Vitalization of Smart Phone Advertising Market in Media Convergence Environment, Korea Broadcast Advertising Commission, Seoul, Korea, (2010)

[6] Y. J. Choi, C. H. Jin, The Effect of Consumers' Lifestyles on Advertising Effectiveness and Preference, The Korean Journal of Advertising, (2013), Vol.24, No.6, pp.69-93, UCI : G704-000514.2013.24.6.006

[7] S. H. Kim, An Analysis of Smartphone Adoption Factors and Behaviors Based on Functional Characteristics, Diffusion Theory, and Technology Acceptance Model, Dong-eui University, Doctoral Dissertation, (2011)

[8] The Future of Wireless Marketing, Carat Interactive, Boston, MA, (2001)

[9] M. Choi, B. Lim, A Study on the Informativeness and the effect on the Purchase Intention based on types of Smart Phone Mobile Advertising, Asia-pacific Journal of Multimedia Services Convergent with Art, Humanities, and Sociology, (2017), Vol.7, No.7, pp.701-714, DOI : 10.35873/ajmahs.2017.7.7.065 
Mobile Media Usage Patterns, Advertising Type Preference, Traits of Advertising, and Mobile Advertising Effects: A Case of South-Eastern Korean Residents

[10] M. Csikszentmihályi, Flow: The Psychology of Optimal Experience ( Harper \& Row), Harper Perennial, (1990)

[11] F. Davis, A Technology Acceptance Model for Empirically Testing New End-User Information Systems: Theory and Results, MIT Sloan School of Management, Doctoral Dissertation, (1986)

[12] R. H. Ducoffe, Advertising Value and Advertising on the Web, Journal of Advertising Research, (1996), Vol.36, No.5, pp.21-35. 